\title{
0 conceito de trabalho escravo da Comissão Pastoral da Terra (CPT): trajetória e dilemas (1970 - dias atuais)
}

Pedro Henrique Santos Queiroz ${ }^{1}$

Resumo: O texto considera a definição de um conceito de trabalho escravo pela Comissão Pastoral da Terra (CPT) no contexto de sua prática de combate ao trabalho escravo contemporâneo no Brasil. São analisados os limites e possibilidades desse conceito com base na observação de afinidades entre a atribuição êmica de significado à escravidão como "metáfora do inaceitável" e algumas das reformulações do conceito kantiano de dignidade humana pelo direito brasileiro e pelo pensamento católico pós-Concílio Vaticano II.

Palavras-Chave: Trabalho escravo contemporâneo; movimento social; dignidade

\section{The Pastoral Land Comission (CPT) concept of slave labour: trajectory} and dilemas (1970 - nowadays)

Abstract: The text considers the definition of a concept of slave labour by the Land Comission (CPT) in the context of its practice of fight against contemporary slave labour in Brasil. The limits and possibilities of this concept are considered from the observation of affinities between the emic attribution of meaning to slavery as a "metaphor of the unacceptable" and some reformulations of the Kantian concept of human dignity by Brazilian law and catholic thought post Second Vatican Council .

1 Programa de Pós Graduação em Ciências Sociais do Instituto de Filosofia e Ciências Humanas (IFCH) da Universidade Estadual de Campinas (UNICAMP), Campinas - Brasil - pedroqueirozpedro@hotmail.com 


\section{Keywords: Contemporary slave labour, social movement, dignity}

\section{Apresentaç̃̃o}

A atuação da Comissão Pastoral da Terra (CPT) no combate ao trabalho escravo foi e tem sido decisiva para a introdução e manutenção desse tema na agenda do debate político brasileiro contemporâneo. Os primeiros casos identificados nos relatos da CPT como de trabalho escravo contemporâneo aconteceram no contexto da expansão da fronteira agrícola na Amazônia brasileira nos anos 1960 e 1970. Tais casos chegaram ao conhecimento dos religiosos atuantes na Prelazia de São Félix do Araguaia (MT) e sua primeira denúncia pública foi de iniciativa do então bispo prelado Dom Pedro Casaldáliga nos primeiros anos da década de 1970, ainda antes da criação oficial da CPT (que foi fundada em 1975). Desde então, e já tendo passado por várias fases, a atuação dos(as) religiosos(as) e leigos(as) que participaram como ativistas ou colaboradores da CPT tem sido de sistematização das informações que lhes chegam, atendimento às vítimas, sensibilização da opinião pública para o problema - inclusive fazendo ações de prevenção com grupos de risco - e encaminhamento de denúncias em instâncias nacionais e internacionais.

Dado que por muito tempo o Estado brasileiro não ofereceu uma definição precisa de trabalho escravo (identificado no Código Penal pela figura de "condição análoga à de escravo"), a atuação da CPT muito cedo teve que lidar com a necessidade prática de elaborar parâmetros próprios de definição conceitual para nomear o problema. Mas antes mesmo de uma definição mais cuidadosa ser sentida como indispensável por essa prática política, a ocorrência do termo trabalho escravo já se encontrava disseminada como categoria êmica (isto é, interna aquele campo de significado cultural) das populações locais e pessoas (jornalistas e policiais rodoviários, por exemplo) de alguma forma em contato com a realidade de exploração do trabalho da população que habitava a fronteira amazônica dos anos 1960 e 1970, funcionando nesse campo discursivo como "metáfora do inaceitável" (Esterci, 1994: 44).

Ao longo do tempo, a essa percepção difusa de determinadas formas de exploração do trabalho como moralmente inaceitáveis vieram se somar outras posições com maior nível de elaboração formal e possibilidade de operacionalização jurídica. Essa trajetória do conceito coincide com um movimento de intensa circulação e diálogo dos ativistas e colaboradores religiosos e leigos da CPT com instâncias governamentais e da sociedade civil, como os poderes executivo, legislativo e judiciário, universidades, imprensa, movimentos sociais, ONGs e fóruns 
internacionais. Essa passagem a outro nível de formalização na elaboração do conceito é não apenas resultado do amadurecimento da compreensão teórica-normativa sobre a questão do trabalho escravo contemporâneo pelos agentes da $\mathrm{CPT}$, mas também, e sobretudo, resposta às novas possibilidades que se abriram à sua atuação após a redemocratização e a passagem dos sucessivos governos civis.

Decorridos sessenta e três anos da inclusão do crime de "reduzir alguém à condição análoga à de escravo" no Código Penal Brasileiro de 1940, foi apenas com a promulgação da Lei n. 10.803, de 2003, que foram indicadas as situações que servem para definir essa condição. A redação atualmente vigente do artigo 149 - que é corroborada pela CPT - define a "condição análoga à de escravo" por uma listagem de situações que a caracterizam isolada ou conjuntamente.

Art. 149 - Reduzir alguém a condição análoga à de escravo, quer submetendo-o a trabalhos forçados ou a jornada exaustiva, quer sujeitando-o a condições degradantes de trabalho, quer restringindo, por qualquer meio, sua locomoção em razão de dívida contraída com o empregador ou preposto; $\$ 1^{\circ}$ Nas mesmas penas incorre quem: I - cerceia o uso de qualquer meio de transporte por parte do trabalhador, com o fim de retê-lo no local de trabalho; II - mantém vigilância ostensiva no local de trabalho ou se apodera de documentos ou objetos pessoais do trabalhador, com o fim de retê-lo no local de trabalho. (Brasil, 1940: S.p.)

A lei n. 10.803, de 2003, corrigiu uma omissão histórica do Estado brasileiro: o texto da Lei Áurea de 1888 aboliu a escravidão sem se dar ao trabalho de definir o que exatamente estava sendo abolido (Figueira, 1999: 166), enquanto que o Código Penal de 1890, o primeiro da recém-proclamada República, sequer mencionava o termo "trabalho escravo" (Fragoso apud CPT, 1993: 42). Não chega a ser um mistério o porquê da falta de rigor conceitual dos pronunciamentos do Estado brasileiro sobre trabalho escravo. Tendo sido um dos últimos países a abolir a escravidão e sem ter feito reforma agrária ou garantido compensação para os ex-escravos e seus descendentes, a formação do moderno mercado de trabalho no Brasil (de compra e venda da mercadoria e força de trabalho) foi marcada pela permissividade com práticas de exploração que só com uso de licença poética poderiam ser identificadas como "trabalho livre" por uma sensibilidade contemporânea² .

2 Exemplos: o colonato nas fazendas de café de São Paulo, a morada na plantation açucareira até os anos 1950 e a imobilização de trabalhadores nos seringais da amazônica até os anos 1990 (Esterci, Ibidem: 62). 
Com o objetivo de buscar uma entrada no campo de indeterminação, desacordo e conflito formado pela ampla diversidade de interesses e valores que se fazem representar na disputa política pela atribuição de sentido à categoria "trabalho escravo", o presente texto irá concentrar-se no exame da evolução do tratamento dado a esse conceito em documentos da CPT e da Igreja Católica sobre o tema, com destaque para os cadernos Conflitos no Campo Brasil, publicação editada regularmente com periodicidade anual pela CPT de 1985 até o presente ${ }^{3}$.

A primeira parte do texto é mais extensa e faz uma leitura contextualizada das posições da CPT, privilegiando o acompanhamento em Conflitos no Campo de suas partes de metodologia, apresentação dos dados e textos de discussão dos resultados sobre trabalho escravo. Na segunda parte, o conceito de trabalho escravo da CPT é revisto com base na identificação de seus principais desafios (institucionalidade, convencimento e singularidade) e do apontamento de notas para a sua crítica.

\section{Dando nomes aos bois: a evolucão do conceito de trabalho escravo da Carta Pastoral (1971) aos cadernos Conflitos no Campo Brasil (1985 - dias atuais).}

Religião declarada de mais de noventa por cento dos brasileiros no censo de 1970, o catolicismo foi uma das formas de expressão de descontentamento mais acessíveis à sociedade civil submetida ao regime de força dos militares no poder. O posicionamento nesse período da Igreja Católica no Brasil como espaço de resistência parece inusitado ${ }^{4}$ quando se considera o comparecimento em massa de importantes setores de sua comunidade de fiéis às manifestações da Marcha da Família com Deus pela Liberdade e o apoio ativo de seu alto clero - a começar pelo então Papa Paulo VI - ao golpe civil militar de $1964^{5}$. As razões desse

3 Todas as edições de Conflitos no Campo encontram-se digitalizadas e disponíveis para consulta no site da CPT em: <https://www.cptnacional.org.br/index.php/publicacoes-2/conflitos-no-campo-brasil>. Acesso em: 11 set. 2019.

4 Porém não inédito: na longa e complexa história da relação entre Igreja Católica e Estado no Brasil (cf. Mainwaring, 1989), houve momentos em que o púlpito permaneceu como um dos poucos espaços postos a salvo do cerceamento à livre expressão de opiniões. O exemplo mais emblemático é talvez o acusatório e mordaz Sermão do Bom Ladrão, proferido pelo Padre Antônio Vieira, em 1655, diante do rei e de altos funcionários do império colonial português.

Essa redoma de proteção não é, no entanto, inquebrável, como o demonstram os vários casos de religiosos perseguidos e mortos por governos autoritários, cf. "Violações de direitos humanos nas igrejas cristãs", no volume de textos temáticos do relatório final da Comissão Nacional da Verdade.

5 Ver a íntegra da nota da Confederação Nacional dos Bispos do Brasil (CNBB) por ocasião dos 40 anos do golpe em Em declaração, CNBB admite que "setores da Igreja" apoiaram golpe de 64, UOL, 02/042014. Disponível em: <https://noticias.uol.com.br/politica/ultimas-noticias/2014/04/o2/em-declaracao-cnbb-admite-que-setores-da-igreja-apoiaram-golpe-de-64.htm>. Acesso em: 11 set. 2019. 
rápido reposicionamento da Igreja Católica no Brasil em relação a um regime cuja instauração havia, em grande parte, apoiado, não se se explicam apenas por circunstâncias locais, mas se relacionam com um quadro mais amplo de mudanças profundas pelas quais vinha passando a Igreja em todo o mundo. $\mathrm{O}$ ritmo intenso de mudanças faz desse um período excepcional na, via de regra, bastante lenta temporalidade de mudança institucional e doutrinária do saecula saeculorum (século dos séculos) católico romano. O Concílio Vaticano II, convocado por João XIII em 1962 e concluído por Paulo VI em 1965, foi um dos marcos mais importantes do esforço de aggionarnamento (atualização) da Igreja frente aos desafios postos pela modernidade ocidental: dentre as várias mudanças ocasionadas por esse Concílio (reunião de todos os bispos), destacam-se as declarações de abandono de reivindicação de ser a única e verdadeira Igreja (Nostra Aetate - nosso tempo), o reconhecimento da liberdade religiosa como direito fundamental (Dignitatis Humanae - da dignidade humana) e o uso das línguas vernaculares na missa, com o oficiante não mais permanecendo de costas para os fiéis (Sacrosantum Concilium - Constituição da sagrada liturgia). Os bispos da América Latina (22\% dos votantes no Concílio), em geral de tendência mais progressista, conseguiram estabelecer coalizões com os bispos do norte da Europa, África e Ásia em momentos cruciais e, com isso, garantiram maior ascendência sobre os resultados do Vaticano II (Wilde, 2007: passim). Essas orientações foram aprofundadas na II Conferência do Episcopado Latino-Americano, em Medellín, de 1968, que definiu a opção pelos pobres como condição de uma Igreja adaptada à realidade do continente. Também a partir do início dos anos 1970, ganhou força na América Latina a teologia da libertação, que propunha uma concepção de Igreja como povo de Deus em caminhada, menos centrada em seus aspectos hierárquicos e mais aberta ao engajamento militante dos religiosos, enfatizando ainda a definição da exclusão social como estado de "pecado social”, cuja caracterização analítica era feita com o instrumental teórico das ciências sociais da época, sobretudo as teorias da dependência e o marxismo.

Os pronunciamentos do sacerdote espanhol claretiano Dom Pedro Casaldáliga, entre 1970 e 1971, quando, então com 42 anos, assumiu a recém-criada Prelazia de São Félix do Araguaia, são representativos desse espírito de mudanças pelo qual passava a Igreja no Brasil e no mundo. São nesses documentos que se encontram as primeiras denúncias públicas de trabalho escravo na história brasileira recente. O informe Escravidão e Feudalismo no Norte do Mato Grosso, publicado em setembro de 1970, quando Casaldáliga ainda era "administrador-apostólico", e a carta pastoral Uma Igreja da Amazônia em Conflito com o Latifúndio e a Marginalização social (Casaldáliga, S.d.), lançada em outubro de 
1971, quando assumiu o título de Bispo Prelado (cargo que ocupou até 2005) O contexto social a que se referem é o das transformações pelas quais vinha passando a região norte do país desde 1966, com a expansão da pecuária bovina de corte apoiada por políticas de incentivo fiscal via SUDAM, o que teve entre suas consequências o crescimento do PIB da região, com maior desmatamento e chegada de fluxos migratórios (Oliveira, 2009: 521-522).

Ambos os textos apresentam para um público mais $\mathrm{amplo}^{7}$ as características gerais de população e território daquela região esquecida do mapa e denunciam os diversos problemas sociais observados pelos religiosos atuantes na área, desde a situação de desassistência pelo poder público e vulnerabilidade social vividas cotidianamente pela população local (indígenas, posseiros e peões) até as constantes violações de seus direitos pelo latifúndio, que se encontrava fartamente servido por políticas de incentivo de eficácia econômica duvidosa ${ }^{8}$. Também em ambos é apresentada documentação de apoio composta por depoimentos (a maioria colhidos em primeira mão), pesquisas acadêmicas, recortes de notícias e documentos oficiais do governo.

Os casos denunciados são de peões aliciados em outras regiões (principalmente sul de Goiás e estados do Nordeste) por intermediários ("gatos") para empreitadas de desmatamento e preparo do pasto que se viam coagidos ao trabalho sob condições degradantes por cobrança de dívidas fraudulentas e uso de violência física. A caracterização das situações de trabalho é feita por Casaldáliga com base na compilação de vários depoimentos de peões e da descrição de suas características gerais como de despersonalização e redução à condição sub-humana: "O peão depois de suportar esse tipo de tratamento, perde sua personalidade." Ainda segundo Casaldáliga, o não reconhecimento do valor humano age tanto sobre a autoimagem do peão, que "Vive, sem sentir que está em

6 No depoimento concedido em 2012 por Casaldáliga a Ana Helena Ribeiro Tavares, disponível em: <https://www.youtube.com/watch?v=8bo_3rUubEY>. Acesso em: 11 set. 2019, o sacerdote relata sua vinda ao Brasil, os primeiros anos de trabalho pastoral no Araguaia, a experiência com a repressão e se refere à Carta de 1971 nesses termos: “(...) foi um grito... Escrevíamos dando nomes aos bois”.

7 A parte final da carta pastoral de outubro, com o título "O Grito desta Igreja”, emite apelos “à dignidade de filhos de Deus e ao seu poder de teimosia e de esperança" dirigidos diretamente "a toda a Igreja do Brasil”, a “CNBB”, aos “católicos' (entre aspas no original) latifundiários que escravizam o povo da nossa região" e às "supremas Autoridades Federais, Presidência da República, Ministério da Justiça, Do Interior, da Agricultura, do Trabalho, INCRA, FUNAI...." acrescentando em nota "À SUDAM, infelizmente não podemos apelar, pois até o momento mostrou-se exclusivamente a serviço do latifúndio" (Casaldáliga, ibidem: 42-43).

8 Sobre a caracterização de "eficácia econômica duvidosa", Brito (1998) e Bunker (1985) apontam algumas das facetas da captura por interesses privados das políticas públicas para o desenvolvimento da Amazônia nessa época. 
condições infra-humanas", como sobre a imagem que dele fazem os moradores locais e fazendeiros que os exploram: "Peão já ganhou conotação depreciativa por parte do povo das vilas, como sendo pessoa sem direito e sem responsabilidade. Os fazendeiros mesmo consideram o peão como raça inferior, com 0 único dever de servir a eles, os 'desbravadores"' (Casaldáliga, ibidem: 26).

As palavras de Casaldáliga coincidem com o sentido da expressão "Escravos da desigualdade", que dá título ao livro de Neide Esterci sobre o uso da noção de escravidão como forma de se referir a formas de exploração verificadas na frente amazônica e em outros contextos. A autora registra o uso desde a década de 1960 pelo menos do termo por vários atores sociais em contato com aquela realidade - imprensa, policiais, agentes do Estado, os próprios peões - e sugere sua importância como indicação de um limite percebido para a desigualdade entre os homens, limite esse que ao ser violado coloca em risco a própria condição humana (daí as metáforas recorrentes de animalidade nos relatos sobre escravidão) e a possibilidade de vida em sociedade:

Determinadas relações de exploração são de tal modo ultrajantes que escravidão passou a denunciar a desigualdade no limite da

desumanização; espécie de metáfora do inaceitável, expressão de um sentimento de indignação que, afortunadamente, sob esta forma afeta segmentos mais amplos do que os obviamente envolvidos na luta pelos direitos. (...) Em todas as fontes pesquisadas, foram encontradas expressões como "dormiam amontoados", "bebiam a mesma água que os cachorros bebiam", "vivemos como porcos", "morando numa pocilga", "transportados que nem gado". Todas referem-se, explicitamente, à aproximação indevida dos homens com os animais. (Esterci, ibidem: 44.)

A CPT foi criada oficialmente em 1975, no encontro das igrejas da Amazônia Legal, realizado entre os dias 19 e 22 de junho, em Goiânia, por iniciativa da Confederação Nacional dos Bispos do Brasil (CNBB), do qual participaram 67 pessoas de 27 dioceses ou prelazias9. Sua atuação é de defesa dos direitos humanos e assessoria militante em conflitos envolvendo, sobretudo, questões de posse e uso da terra e recursos naturais ${ }^{10}$. A atividade de registro e documentação

9 Dentre as quais, a de São Félix do Araguaia, tendo Casaldáliga sido vice-presidente da CPT de 1981 a 1983.

10 Com informações dos textos histórico e missão da seção quem somos no site <www.cptnacional.org. br>; verbete temático Comissão Pastoral da Terra no Dicionário Histórico Biográfico CPDOC/FGV. Disponível em: <http://www.fgv.br/cpdoc/acervo/dicionarios/verbete-tematico/comissao-pastoral-da-terra-cpt>. Acesso em: 11 set. 2019. E matéria Há 40 anos nascia a CPT, Brasil de Fato, 09/06/2015. Disponível em: <https://www.brasildefato.com.br/node/32223/>. Acesso em: 11 set. 2019. 
é assumida nesse momento mais como esforço de resistência contra o risco de exclusão da memória de sofrimento e luta dos trabalhadores, o que em muitos casos significava nada mais do que a prestação dos ritos funerários condignos às vítimas do trabalho escravo (Moraes, S.d.). O depoimento do Padre e pesquisador Ricardo Resende Figueira sobre sua experiência na região do Araguaia oferece um registro da perplexidade e sentimento de indignação impotente dos religiosos nessa primeira fase de atuação de combate ao trabalho escravo:

Os STRs (Sindicatos de Trabalhadores Rurais) e a Igreja não sabiam como enfrentar o problema no Araguaia. A área vivia sob o temor por causa da repressão à guerrilha - desencadeada entre 1972 e 1974 - e a sociedade civil organizada era especialmente frágil (...) o escritório da CPT de Conceição do Araguaia só foi instalado em 1977. Logo recebeu notícias de fazendas com trabalho escravo, violência e assassinatos de peões. Mas essas informações chegavam atrasadas e não havia como levantar provas, pois, sendo o trabalho escravo temporário - começando no final de março, terminava com as primeiras chuvas -, os sobreviventes se dispersavam ou retornavam ao Estado de origem (...) A primeira atitude da equipe da CPT foi de surpresa e indignação moral; a segunda registra as informações, sem saber exatamente o que fazer com os dados. (Figueira, ibidem: 176)

A publicação do primeiro caderno Conflitos no Campo Brasil (CC) é de 1985 e sua concepção é atribuída ao Padre Mário Aldighieri, secretário executivo da CPT de 1981 a 1983 (CPT, 2014). Esse é o ano da eleição indireta do primeiro presidente civil desde o golpe de 1964 e da publicação do relatório Brasil Nunca Mais, iniciativa ecumênica e pioneira de compilação e denúncia sistemática dos casos de violações de direitos humanos ocorridos durante a ditadura. Também nesse ano o recém-criado Ministério da Reforma e Desenvolvimento Agrário (MIRAD) admitiu em uma série de relatórios a existência de trabalho escravo no país e legitimou registros produzidos pelo movimento social, encaminhando-os à Anti Slavery International (ASI), organização internacional dedicada ao combate ao trabalho escravo. Esse é, segundo Esterci, o ponto de início de uma nova "verdade oficial" sobre o problema, que até então era simplesmente ignorado pelo Estado (Esterci, ibidem: 25). Apesar das muitas variações de modelo pelo qual passou ao longo do tempo, a proposta editorial dos CC permanece basicamente a mesma desde suas origens, seguindo uma estruturação em três eixos: conflitos pela posse da terra e de recursos naturais, conflitos trabalhistas (dentre os quais, trabalho escravo) e violência contra a pessoa (ameaças, agressões, assassinatos). Cada edição 
contém a apresentação das várias ocorrências de conflito em tabelas organizadas segundo uma tipologia própria e textos de análise dos resultados gerais e de alguns casos mais emblemáticos.

Os informes dos primeiros CC sobre trabalho escravo têm problemas de apresentação confusa dos dados e fundamentação conceitual quase inexistente. Desde a primeira edição (1985), há registro de casos em estados para além da região amazônica (até 1990: PI, SP, BA, RJ e RS ${ }^{11}$ ), embora essa concentre a maior parte dos casos (sobretudo PA e MT). De 1985 a 1990 são denunciados ao todo 94 casos com número estimado de 8025 vítimas. No CC de 1990 é publicada pela primeira vez a seção "Fontes de pesquisa" com a listagem de publicações de imprensa usadas para recolhimento de informações. A seção "Nossos critérios de trabalho", de exposição das escolhas metodológicas, é publicada pela primeira vez no CC de 1987 e a passagem sobre trabalho escravo (como caso específico de "conflito trabalhista") permanece inalterada até o CCC de 1995: "Conflitos trabalhistas são aqueles que dizem respeito à relação de trabalho patrão X empregado (por exemplo, que desrespeitem as normas estabelecidas pela CLT), ocorrência de trabalho escravo, regime de 'barracão', greves em usinas e plantações etc." (CPT, 1988: 6). Embora essa definição de "conflitos trabalhistas" mencione também "acidentes de trabalho" e "questões sindicais", desde o CC 1992, apenas os casos de trabalho escravo são registrados nessa categoria.

O texto "a luta pelo trabalho livre", publicado no CC de 1990, é o primeiro a apresentar uma discussão mais detida sobre os fundamentos normativos da categoria trabalho escravo. A estrutura do texto é composta por três linhas argumentativas: legal, antropológica e evangélica. Na primeira, é endossado o entendimento dos juristas Magalhães Noronha e Cláudio Fragoso ${ }^{12}$ sobre o artigo 149 do Código Penal, segundo o qual a condição "análoga a de escravo" se configuraria pela restrição da liberdade do trabalhador. Também são mencionados como possíveis instrumentos legais de combate ao trabalho escravo a Convenção 105 da OIT, ratificada pelo governo brasileiro em 1965, e o artigo IV da Declaração Universal de Direitos Humanos. A argumentação antropológica é com base em relato de casos (PA, MT e GO) em que trabalhadores foram submetidos a aprisionamento, espancamentos e sevícias sexuais. A argumentação evangélica aparece aqui como síntese das perspectivas jurídico-legal e antropológica e indica o uso do princípio da dignidade da pessoa humana como fundamento do

\footnotetext{
11 Um dos problemas mais graves desses primeiros CC é que não é possível identificar neles o tipo de atividade econômica em que era empregado e quais modalidades assumia o trabalho escravo, principalmente em outros contextos que não os da frente amazônica.

12 Cláudio Fragoso é citado novamente no CC 1992.
} 
conceito de trabalho escravo, posição essa que só apareceria nesses termos no texto dos CC de alguns anos depois:

Redução de pessoas à condição de escravos não é somente ilegal. É imoral, abjeto, antievangélico. Envergonha a todos os seres humanos. A problemática do campo grita por justiça, que vai desde uma reforma agrária justa e uma política agrícola que contemple o pequeno produtor; até o respeito aos direitos do trabalhador rural assalariado, principalmente os temporários; $E$ a aceitação dos trabalhadores como seres humanos criados à imagem e semethança de Deus e não como animais de carga (CPT, 1991: 11, Grifos meus).

Os CC da década de 1990 mostram uma melhoria sensível na apresentação dos dados sobre trabalho escravo: além da padronização no formato das tabelas, são incluídos gráficos e mapas que facilitam o acompanhamento de tendências de distribuição espacial e temporal dos casos. Também há ganho substantivo nas definições conceituais utilizadas. No CC de 1995 aparece o tópico "Critérios para a caracterização de trabalho escravo" em destaque ao final da seção "Nossos critérios de trabalho" (que mantém a redação dos anos anteriores sobre "conflitos trabalhistas"). De acordo com essa formulação, "o elemento central e essencial é a sujeição do trabalhador" (física ou psicológica). A dívida "crescente e impagável" é mencionada como "meio de atingir a sujeição", que, por si só, já "caracteriza suficientemente o trabalho escravo", esse que pode ainda ser agravado por "situações agudas", como: "Presença de pistoleiros ou vigias armados impedindo a saída dos trabalhadores, maus-tratos, ameaças, jornadas excessivas, alimentação de péssima qualidade e insuficiente, falta de assistência médica, isolamento do local de trabalho e apreensão de documentos pessoais" (CPT, 1996: 45).

Note-se que a listagem das "situações agudas" abrangidas por esse conceito de trabalho escravo vai além dos "fortes indícios de trabalho forçado", citados no documento de "Procedimentos da Inspeção do Trabalho na Área Rural", de 1994 - até então o mais próximo de uma caracterização oficial de trabalho escravo $^{13}$-, que não fazia referência a jornadas excessivas ou condições de trabalho inadequadas:

Constitui-se forte indício de trabalho forçado a situação em que o trabalhador é reduzido a condição análoga à de escravo, por meio de fraude, dívida, retenção de salários, retenção de documentos, ameaças ou violências que impliquem o cerceamento da liberdade dele e/ou de seus familiares em

13 Note-se que o termo usado nesta instrução não é trabalho escravo, ou condição análoga à de escravo, como no Código Penal, mas trabalho forçado. Para uma análise desse documento, ver Sutton, 1994. 
deixar o local onde presta seus serviços, ou mesmo quando o empregador se negar a fornecer transporte para que ele se retire do local para onde foi levado, não havendo outros meios de sair em condições seguras, devido às dificuldades de ordem econômica ou física da região. (Brasil, 1994)

A busca por legitimação institucional foi um dos principais incentivos para uma formalização mais cuidadosa do conceito de trabalho escravo da CPT. Com a maior possibilidade de colaboração com órgãos oficiais, tornou-se premente que tal conceito dispusesse de definições aproveitáveis para a operacionalização jurídica-criminal do combate ao trabalho escravo, bem como à formulação de diretrizes para políticas públicas para sua erradicação. Entre 1992 e 1994, a CPT fez pronunciamentos na Comissão de Direitos Humanos das Nações Unidas e em espaços da OIT e OEA para denunciar a ocorrência de trabalho escravo no Brasil. É também desse período o início da colaboração com ONGs estrangeiras com a já citada Anti Slavery International e a Humans Rights Watch. No plano nacional, a CPT participou ativamente de todos os fóruns criados pelo governo federal para a discussão e elaboração de políticas de combate ao trabalho escravo, desde o Programa de Erradicação do Trabalho Forçado (PERFOR), do governo Collor, até a Comissão Nacional de Erradicação do Trabalho Escravo (CONATRAE), do governo Lula, passando pelo Grupo Executivo de Repressão ao Trabalho Forçado (GERTRAF), do governo FHC. A possibilidade desse tipo de colaboração entre movimento social e Estado variou bastante de acordo com as circunstâncias, como indicam as diversas críticas, elogios e cobranças registrados nos CCC aos governantes (presidentes e governadores), agentes da Lei e funcionários dos Ministério Público e do Trabalho ${ }^{14}$.

Segundo avaliação posterior da própria CPT, os CC de 1991 a 1995 registram um valor exorbitante de trabalhadores envolvidos nas denúncias, acumulando para o período um total de 91.148 pessoas (média anual 18.230 envolvidos), embora a quantidade de casos tenha se mantido oscilante em torno de 20 casos anuais. Isso se deve à importância adquirida nesse período pelas denúncias de trabalho escravo nas carvoarias de Minas Gerais e Mato Grosso do Sul e à dificuldade de acesso aos locais de trabalho, de forma que as estimativas do número de vítimas nesses casos eram feitas com base em informações muito precárias, como as de número de fornos instalados e área plantada (Plassat, 2009: 90-93). O CC de 1992, por exemplo, registra 4 casos na região Centro-Oeste envolvendo 8413 pessoas e 5 casos no Norte com 165 pessoas envolvidas (CPT, 1993: 9). Em

14 No CC 1994, por exemplo, a proatividade das Delegacias Regionais do Trabalho do Mato Grosso do Sul e Minas Gerais é contraposta à leniência da DRT do Pará (CPT 1995: 29). 
1995, são realizadas as primeiras atividades dos Grupos Especiais, com as quais a CPT passa a colaborar na condição de principal fornecedora de denúncias.

No CC de 1997, a seção "nossos critérios de trabalho" veio acompanhada de nota indicando o processo de "ampla revisão" e caráter provisório dos "critérios de documentação" ali apresentados ${ }^{15}$. A parte sobre "conflitos trabalhistas" se encontra totalmente reformulada e agora incorpora um dispositivo formado por três conceitos: trabalho escravo (cuja definição é a mesma do CC de 1995), superexploração e desrespeito trabalhista. Superexploração diz respeito à "esfera salarial" e indica "situações em que as horas de trabalho não pagas pelo explorador excedem a taxa normal de exploração do trabalho" e desrespeito trabalhista "tem como referência a legislação vigente e está ligado às condições de trabalho" (CPT, 1998: 72-73). Essas definições permanecem inalteradas ${ }^{16}$ nos CC seguintes até 2011, quando a definição de trabalho escravo indicada na seção de metodologia passa a ser a do artigo 149 do Código Penal desde a sua reformulação em 2003, como segue:

Na compreensão do que é Trabalho Escravo, a CPT segue o definido pelo artigo 149, do Código Penal Brasileiro, atualizado pela Lei $n^{\circ} 10.803$, de 11.12.2003, que o caracteriza por submeter alguém a trabalhos forçados ou a jornada exaustiva, ou por sujeitá-lo a condições degradantes de trabalho, ou quando se restringe, por qualquer meio, sua locomoção em razão de dívida contraída com o empregador ou preposto, ou quando se cerceia o uso de qualquer meio de transporte por parte do trabalhador, com o fim de retê-lo no local de trabalho, ou quando se mantém vigilância ostensiva no local de trabalho, ou se apodera de documentos ou objetos pessoais do trabalhador, com o fim de retê-lo no local de trabalho (CPT, 2012: 10-11).

O processo de debate interno a que se refere a nota no CC de 1997 coincide com a indicação do dominicano Dom Tomás Balduíno para a presidência da

15 Essa nota continua sendo publicada na seção de metodologia de todos os CC até o de 2001.

16 Apenas no CC de 1997 essas definições de superexploração e desrespeito trabalhista são acompanhadas por uma lista de situações de ocorrência. Para a superexploração: “a) atraso no pagamento; b) descontos ilegais; c) não pagamento de horas extras; d) jornada de trabalho excessiva; e) horas extra além do permitido; f) não pagamento do FGTS; g) demissão sem pagamento de indenização; $h$ ) não pagamento de adicionais (insalubridade, periculosidade etc.)".

Para desrespeito trabalhista: a) Impedimento de intervalo, repouso semanal, feriados, férias; b) não fornecimento de água potável; c) assistência médica inexistente ou precária; d) alojamento inadequado; e) alimentação insuficiente ou de má qualidade; falta de meios para o aquecimento da comida; f) transporte inadequado em veículos impróprios e com instrumentos de trabalho, sacas de agrotóxico etc. junto com os trabalhadores; g) uso indiscriminado de agrotóxicos e armazenagem em locais de possível risco para os trabalhadores; h) falta de equipamento de proteção individual". 
CPT, e teve como principal acontecimento o Seminário Nacional sobre Trabalho Escravo, que foi realizado em Goiânia entre os dias 7 e 8 de abril daquele ano. Dentre as várias contribuições a esse seminário, destaca-se por seu teor polêmico a de José de Souza Martins, publicada com o título A escravidão nos dias de hoje e as ciladas de interpretação: reflexão sobre riscos de intervenção subinformada. Nesse texto, o sociólogo acusa o que percebia como falta de rigor conceitual no denuncismo praticado por alguns dos ativistas envolvidos no combate ao trabalho escravo e sugere o uso da categoria superexploração como mais adequada para se referir a situações como as encontradas nas carvoarias e canaviais em que não se configura trabalho escravo, mas ainda assim "São casos em que as horas cedidas ao patrão, imperceptivelmente, sem pagamento, excedem a taxa normal de exploração do trabalho ${ }^{17}$ - aquilo que o trabalhador ganha é, a médio prazo, insuficiente para assegurar sua sobrevivência e a de sua família" (Martins, 1999: 130). Essa posição coincide com a que já vinha começando a ser adotada pela CPT em sua prática, ao que indica essa passagem do CC de 1996, em que é citado depoimento do padre Alfredo Prandel, da regional do Mato Grosso do Sul:

As condições de vida e trabalho nas carvoarias continuam péssimas, a relação patrão-empregado não avançou em nada, a não ser na eliminação da dívida, e quando esta existe, o patrão diz que fica por conta do acerto, saindo o trabalhador sem nada. Mas isso não caracteriza o trabalho escravo". Assim, a retirada do mecanismo da dívida que na relação de trabalho caracteriza o trabalho escravo, faz essa diferença significativa. Entretanto, permanece a forma ainda grave de relação de trabalho, chamada superexploração, do mesmo modo degradante. (CPT, 1997: 50)

No CC de 1997, há uma grande redução no número de vítimas de trabalho escravo em comparação com os anos anteriores (26.047 em 1995, 2.487 em 1996 e 817 em 1997). Além da inclusão das denúncias de superexploração, essa diminuição se explica pela decisão da regional da CPT no Pará (aparentemente, seguida depois pelas demais regionais) em registrar apenas os casos (fazendas e firmas) e número de trabalhadores libertados que constassem dos relatórios do grupo móvel de fiscalização recém-implantado na região (CPT, 1998: 62). No CC de 2000, é feito um balanço em que a atuação dos grupos móveis, iniciada

17 Note-se que a expressão "taxa normal de exploração", usada por Martins é ipsis litteris a mesma da definição de superexploração da seção de metodologia dos CC de 1995 em diante, como exposto anteriormente. 
com o Gertraf, é saudada como avanço em relação à "ineficácia total" dos esforços anteriores e seus resultados reconhecidos como "efetivos, embora insuficientes". Nessa avaliação, o Gertraf teve como ponto positivo a identificação da necessidade de escapar das pressões das oligarquias locais, o que desdobrou nos procedimentos de comando único em Brasília, sigilo das operações e seleção criteriosa dos funcionários envolvidos. Como pontos negativos, são citados os vazamentos de informação, atrasos, a não realização de fiscalizações por indisponibilidade de meios logísticos, e, por fim, a continuada morosidade da justiça em processar os casos flagrados pelas equipes de fiscalização (CPT, 2001: 70).

Os CC dos anos 2000 mostram um aumento no número de registros de trabalho escravo acompanhando a aprovação da Lei n. 10.803 e o aumento do número de ações dos grupos móveis de fiscalização, agora dispondo de mais recursos pessoais e financeiros, sob impulso da Conatrae (de 30 operações em 2002 para 67 em 2003 e, no auge, 175 operações em 2014). Com isso, pôde-se observar uma maior dispersão geográfica dos casos de trabalho escravo: se de 1995 a 2002 houve ocorrência de libertação pelas equipes de fiscalização em apenas 10 estados, de 2003 em diante todos os Estados, com exceção do Distrito Federal, tiveram ações que resultaram em libertação de trabalhadores. O setor sucroalcooleiro aparece em destaque como a grande "novidade" da década: em 2007, mais da metade dos trabalhadores libertados foram em fazendas de cana de açúcar (Sakamoto, 2008: 110), chamando atenção para uma realidade de exploração do trabalho que, entre 1999-2006, foi responsável por 72 mortos e 400 feridos por excesso de trabalho nos canaviais paulistas, segundo levantamento da socióloga Maria Aparecida Moraes Silva (2006: 14). Além da adoção do conceito de trabalho escravo do Código Penal, reformulado em 2003, a principal inovação metodológica dos CC é a maior transparência (disclosure) com relação aos procedimentos de coleta e encaminhamento de denúncias: no CC de 2010 há um extenso relato sobre as várias trajetórias que levam os denunciantes a CPT, o perfil desses depoentes e os itens que compõem o "Formulário de Recepção de Denúncia de Trabalho Escravo" (CPT, 2011: 20). A maior parte dessas informações, bem como sobre o banco de dados de elaboração própria da CPT, passam a constar na seção de metodologia dos CC seguintes, logo após o trecho com as definições conceituais utilizadas.

Em termos normativos, a principal inovação dos CC desse período é o uso mais decidido e bem elaborado ${ }^{18}$ do princípio da dignidade da pessoa humana

18 Nos CC 1991, 1992 e 1994 há referências esparsas e subdesenvolvidas ao princípio da dignidade como fundamento do conceito de trabalho escravo. 
como fundamento da categoria trabalho escravo. O princípio da dignidade é endossado a) em sua formulação cristã, tal como exposto no texto de apresentação do CC de 2000, assinado por Roberto Malvezzi, coordenador geral da CPT: “(...) cada vida humana vale em si mesma e é inviolável, porque cada ser humano carrega a santidade do próprio Deus. Cada ser humano é único e irrepetível” (CPT, 2001: 5), sendo essa uma linha teológica consagrada na constituição pastoral Gaudium et Spes (Alegria e Esperança), lançada no último ano do Concílio Vaticano $\mathrm{II}^{19} \mathrm{e}$ b) em sua formulação laica, desde sua elaboração clássica na tradição filosófica ocidental por Immanuel Kant, no século XVIII, que foi reformulada pela moderna Filosofia do Direito e assumida como um dos cinco fundamentos do Estado Democrático de Direito pela Constituição Federal de 1988. O argumento é resumido no CC de 2006 por Maria José Souza Moraes, assessora jurídica da CPT, ligada à Prelazia de São Félix do Araguaia:

Para Kant, a dignidade é o valor de que se reveste tudo aquilo que não tem preço, ou seja, não é passível de ser substituído por um equivalente. Portanto, a dignidade é uma qualidade inerente aos seres humanos enquanto entes morais. $\mathrm{O}$ ser humano exerce de forma autônoma a sua razão prática e, assim, constrói distintas personalidades humanas. Consequentemente, a dignidade é inseparável da autonomia para o exercício da razão prática, e é por esse motivo que apenas os seres humanos revestem-se de dignidade. Alexandre dos Santos Cunha elucida que o grande legado do pensamento Kantiano para a filosofia dos direitos humanos é a igualdade na atribuição da dignidade. Percebemos então, que as raízes históricas do princípio da dignidade humana estão vinculadas ao ideário Kantiano, mormente a partir das noções de que o ser humano é um ente dotado de autonomia racional e que nunca deve ser encarado como um instrumento para satisfação dos interesses de outrem. (Moraes, 2007: 126)

A persistência dos discursos de negação da existência de trabalho escravo no Brasil contemporâneo foi um dos principais incentivos percebidos pela CPT para a produção de um conceito mais resistente a eventuais questionamentos e com maior poder de convencimento no debate público. O quão foram bem-sucedidos nessa tarefa pode ser atestado por episódio recente que

19 Nesse documento, a dignidade é a afirmação do homem como "centro e termo" para "tudo quanto existe sobre a terra" por ter sido ele criado "à imagem de Deus, capaz de conhecer e amar seu Criador", de forma que "Exige, portanto, a dignidade do homem que ele proceda segundo a própria consciência e por livre adesão, ou seja movido e induzido pessoalmente desde dentro e não levado por cegos impulsos interiores ou por mera coação externa" (Vaticano, sd: sp). 
representou provavelmente a maior ameaça até agora acontecida de retrocesso na política do governo brasileiro de combate ao trabalho escravo. Trata-se da publicação da portaria n. 1.129 de 2017, que propunha a alteração do conceito jurídico de "condição análoga à de escravo", excluindo da definição do artigo 149 do Código Penal as expressões "condições degradantes de trabalho" e "jornadas exaustivas", além de dificultar o acesso às informações da chamada "lista suja" ${ }^{20}$. O governo foi obrigado a retroceder após forte reação da sociedade civil, com declarações contrárias bem distribuídas ao longo do espectro político esquerda/direita, sendo emblemático desse movimento a tomada de posição clara e decidida do grupo Globo, mais importante empresa do oligopólio midiático nacional, que atacou a portaria n. 1.129 em editorial, com produção de várias reportagens minuciosas sobre o assunto e apoio de seus principais colunistas ${ }^{21}$.

\section{Notas para a crítica do conceito de trabalho escravo da CPT}

É possível identificar três grandes desafios enfrentados pela definição de trabalho escravo da CPT, quais sejam: a) da institucionalidade (que seja um conceito passível de operacionalização jurídico criminal); b) do convencimento (que seja um conceito com bom desempenho no debate público de ideias); e c) da singularidade, sendo esta uma dificuldade comum a toda e qualquer construção de sentido sob a forma conceito, essa figura de linguagem que, conforme Nietzsche, serve para "atribuir identidade ao não idêntico" (Nietzsche, 1983: 75). Assim entendido, o desafio da singularidade passa a ser o de determinar o que identifica as várias manifestações particulares de trabalho escravo, essa "grande violência que se utiliza de várias modalidades de violência para se manter" (CPT, 1995: 25), seja na fronteira amazônica da década de 1970, nos fornos de carvão do Mato Grosso na década de 1990 ou nos canaviais paulistas da década de 2000. Em outras palavras, trata-se de estabelecer se é justificável e relevante a abstração das especificidades de cada caso em favor da afirmação de sua unidade.

20 Outra grande inovação da política de combate ao trabalho resultado da Conatrae, a Lista Suja foi instituída em outubro de 2004 e todos os anos desde então divulga os nomes dos empresários e firmas flagrados com trabalho análogo ao escravo, o que, além da publicidade negativa gerada também implica na suspensão da possibilidade de tomar empréstimos em bancos públicos.

21 Ver o editoral de O Globo de 18 de outubro "Portaria sobre trabalho escravo é um retrocesso". Disponível em: $<$ https://oglobo.globo.com/opiniao/portaria-sobre-trabalho-escravo-um-retrocesso-21958285>. Acesso em: 11 set. 2019. E a coluna de Miriam Leitão "Agronegócio se deixa representar pelas forças do atraso" do dia 16. Disponível em: <http://blogs.oglobo.globo.com/miriam-leitao/post/agronegocio-se-deixa-representar-pelas-forcas-do-atraso.html>. Acesso em: 11 set. 2019. 
Como indicado, no enfrentamento dessas três dificuldades a CPT optou pelo uso do princípio da dignidade da pessoa humana como fundamento normativo do conceito de trabalho escravo. Ao fazê-lo, optou pelo desenvolvimento de algumas das implicações doutrinárias possíveis das afinidades eletivas encontradas entre o universalismo da fé cristã (a palavra grega katholikos é traduzida como "universal" em português) e aquele anunciado nas declarações universais de direitos do homem e do cidadão, sendo a primeira delas a da Revolução Francesa, de 1789. Para que o desenvolvimento teológico dessas afinidades entre universalismo cristão e afirmação dos direitos humanos pudesse ser aceito e explorado com mais desembaraço pelo dogma católico romano foi necessário um longo processo de arrefecimento daquela polarização entre anticlericalismo revolucionário e reacionarismo clerical, cuja origem pode ser atribuída, pelo menos em parte, como propõe Tocqueville, à circunstância de os membros da Igreja pertencerem formalmente à classe dominante como Segundo Estado durante a vigência do Antigo Regime (Lepargneur, 1977: passim).

Em termos teóricos, as ideias de Kant (o "filósofo alemão da revolução francesa”, na expressão divertida de Karl Marx) pareceram o caminho natural a seguir por facilitarem a afirmação simultânea da dignidade do homem como imagem e semelhança de Deus e como sujeito dos direitos da Declaração do Homem e do Cidadão. A definição do conceito de trabalho escravo nesses termos deve, no entanto, enfrentar uma série de dificuldades que surgem tão logo a avaliação das relações de exploração do trabalho seja submetida aos critérios do imperativo categórico kantiano ("Procede apenas segundo aquela máxima, em virtude da qual podes querer ao mesmo tempo que ela se tome em lei universal"). As dificuldades surgem do conflito colocado pela relação de compra e venda da mercadoria força de trabalho entre as exigências de dignidade da pessoa humana ("Age de tal forma que uses a humanidade, tanto na tua pessoa, como na pessoa de qualquer outro, sempre e ao mesmo tempo como fim e nunca simplesmente como meio") e autonomia da vontade ("Age como se fosses, através de suas máximas, sempre um membro legislador no reino universal dos fins") (Kant, 2009). Dado que a mercadoria força de trabalho tem a peculiaridade de ser indissociável de seu portador e que o trabalhador se vê durante a jornada de trabalho ocupado com a consecução de fins que não foram determinados autonomamente por sua vontade racional, é difícil estabelecer a priori um patamar por meio do qual a exploração do trabalho implicaria em violação da dignidade.

Esse dilema se faz sentir nas definições conceituais usadas pela CPT, notadamente na instabilidade entre os conceitos de superexploração e trabalho escravo. A questão que se coloca é se não haveria também relação de sujeição 
(que caracteriza o trabalho escravo para $\mathrm{CPT}$ ) ou de heteronomia da vontade e violação da dignidade humana (nos termos de Kant) na relação de trabalho superexplorado ou mesmo na relação de exploração "normal". Como expõe Maria José de Souza Moraes no CC 2006:

A superexploração do trabalhador é tão grave quanto o trabalho escravo, inclusive porque a linha divisória (se é que há), entre uma condição e a outra, é tão tênue que é difícil saber quando termina uma e começa a outra. Combater a superexploração é, com certeza, ir cerrando a porta de entrada para o trabalho escravo. (Moraes, ibidem: 127)

A solução proposta por José de Souza Martins e acatada pela CPT (vide nota 16 supra) na verdade pouco ajuda a traçar essa "linha divisória (se é que há)", já que a operacionalização da ideia de taxa normal de exploração do trabalho requereria uma definição muito difícil sobre as condições em que o preço da mercadoria força de trabalho corresponde ao seu valor (tempo de trabalho socialmente necessário à reprodução da própria força de trabalho). Essa dificuldade está dada não apenas pela multiplicação de necessidades, que é típica do mundo moderno (Martins, Ibidem: 130), mas também porque remete a um dos problemas de mais difícil solução no interior da teoria econômica marxista (que compõe a referência de fundo das observações de Martins), qual seja o da transformação do valor (tempo de trabalho socialmente necessário) em preço (expressão monetária do valor). $\mathrm{O}$ uso dessa terminologia remete ainda à teoria da dependência de Rui Mauro Marini, que define a condição de superexploração como "princípio fundamental da economia subdesenvolvida":

Uma parte da mais-valia que aí se produz (na América-Latina) é drenada para as economias centrais, seja mediante a estrutura de preços vigente no mercado mundial e as práticas financeiras impostas por essas economias, seja através da ação direta das inversões forâneas no campo da produção. As classes dominantes locais tratam de ressarcir-se dessa perda aumentando o valor absoluto da mais-valia criada pelos trabalhadores agrícolas ou mineiros, quer dizer, submetendo-os a um processo de superexploração (Marini, 1969: 8).

Não é por acaso que a fundamentação dos conceitos usados pela CPT em sua prática de combate ao trabalho escravo remeta à discussão de modelos gerais de explicação da singularidade do desenvolvimento histórico do capitalismo em uma economia periférica, como é o caso da relação exposta entre o conceito de superexploração e a teoria da dependência de Rui Mauro Marini. Isso porque o cerne da questão enfrentada pela produção de um conceito de trabalho escravo 
está na identificação de um nível de exploração que seja moralmente aceitável e compatível com o "nível civilizatório atual", como argumentado na nota pública da CPT de novembro de 2013 a respeito de uma tentativa acontecida naquele ano de alterar o conceito legal de trabalho escravo:

O escravo moderno encontrado pelos competentes auditores fiscais do trabalho, procuradores e policiais, integrantes dos grupos móveis especializados, não é mais aquele sujeito sem direitos (ou melhor: não-sujeito), preso a correntes, como no tempo da Colônia ou do Império. A analogia da sua situação em relação àquela do antigo escravo se dá necessariamente por meio de critérios modernos, relacionados ao nível civilizatório atual (CPT, 2014).

A tensão encerrada no conceito de trabalho escravo da CPT é definida pela coexistência conflituosa em seu interior de exigências de garantia, alargamento e superação da dignidade possível na relação de exploração capitalista do trabalho. É por essa razão que, embora no exercício aqui apresentado o combate ao trabalho escravo contemporâneo tenha sido analisado à parte, na prática da CPT essa reivindicação foi indissociada das disputas sobre o modelo de desenvolvimento econômico e o tipo de sociedade que queremos ser. E é por essa razão que, na trajetória de prática política da CPT, a luta contra o trabalho escravo esteve associada às lutas por propriedade da terra, respeito ao meio ambiente $\mathrm{e}$ direitos humanos.

\section{Conclusões}

A principal dificuldade enfrentada pelo uso da noção de dignidade humana como fundamento do conceito de trabalho escravo é a mesma que encontra qualquer argumentação antropocêntrica de busca pelas condições de validade da norma jurídica em um contexto de direito pós-convencional. Os esforços de produção de discursos de convencimento e, especialmente, de operacionalização jurídica da prática de combate ao trabalho escravo contemporâneo precisam, assim, encontrar alguma solução satisfatória entre as exigências de facticidade e validade do direito, isto é, entre "o princípio da segurança jurídica e a pretensão de tomar decisões corretas" (Habermas, 1997: 245), sendo que essas respostas devem ser buscadas considerando a “(...) situação de uma sociedade profanizada onde as ordens normativas têm que ser mantidas sem garantias meta-sociais. E as certezas do mundo da vida, já pluralizadas e cada vez mais diferenciadas, não fornecem uma compensação suficiente para esse déficit (Ibidem: 45). 
Em termos de estrutura lógica da argumentação, a dificuldade referida não muda tanto, seja o princípio da dignidade apresentado como afirmação bíblica da dignidade do homem porque criado à imagem e semelhança de Deus ou imperativo categórico de que cada pessoa seja considerada como fim e não como meio para a ação. Tanto em um como em outro caso, a fundamentação do conceito de trabalho escravo pela noção de dignidade permanece vulnerável aos problemas reunidos pelos racionalistas críticos no trilema de Munchausen: “(...) qualquer tentativa de estabelecer fundamentos últimos leva seja a uma regressão infinita, seja a um círculo lógico, seja à interrupção dogmática do processo de raciocínio e de argumentação, pela seleção arbitrária de certas premissas". (Rouanet, 2007: 214)

A identificação do nível moralmente aceitável de exploração do trabalho, que informa a operacionalidade do conceito de trabalho escravo, não tem, assim, como evitar a arbitragem da colisão eventual entre princípios consagrados no ordenamento jurídico existente: no caso específico, entre os princípios fundamentais de dignidade da pessoa humana e dos valores sociais da livre iniciativa, citados no artigo primeiro da Constituição Federal de 1988 (Brasil, 2018: 15). Nesse sentido, cabe analisar mais de perto algumas das vantagens e desvantagens da escolha pelo uso do referencial teórico marxista como um dos elementos de referência de fundo da distinção conceitual entre trabalho escravo, superexploração e desrespeito trabalhista. Se há ganho claro na explicitação do conflito de interesses envolvidos na relação de exploração do trabalho, por outro lado o vínculo entre a teoria da alienação e a crítica ao Estado burguês em Marx pode levar à dissolução da possibilidade de regulação jurídica dos conflitos no exercício puro e simples da força maior em um contexto de luta de classes, como neste trecho particularmente mordaz do capítulo sobre a jornada de trabalho em O Capital, por exemplo:

O capitalista faz valer seus direitos como comprador quando tenta prolongar o máximo possível a jornada de trabalho e transformar, onde for possível, uma jornada de trabalho em duas. (...) e o trabalhador faz valer seu direito como vendedor quando quer limitar a jornada de trabalho a uma duração normal determinada. Tem-se aqui, portanto, uma antinomia, um direito contra outro direito, ambos igualmente apoiados na lei da troca de mercadorias. Entre direitos iguais, quem decide é a força. (Marx, 2013: 309)

Nesse sentido, talvez fosse produtivo - em termos de melhoria da qualidade da argumentação e maior esclarecimento de objetivos estratégicos (seja de 
constituição de Estado social ou transição para o socialismo) - que os agentes da CPT envolvidos na luta contra o trabalho escravo buscassem incluir nos momentos de reflexão sobre sua própria prática um diálogo com a produção de outros momentos políticos e intelectuais que também buscaram associar a crítica marxista à alienação do trabalho com os termos da ética kantiana, notadamente na social-democracia alemã (Bernstein, 1997) e no austromarxismo (Adler, 1975) do fim do século XIX e início do XX.

\section{Referências}

ADLER, Max. Kant und der Marxismus: Gesammelt Aufsatze zur erkenntniskritik und Theorie des Sozialen. Aalen, Scientia, 1975.

BRASIL. Decreto Lei n. 2.848 de 07 de dezembro de 1940. Código Penal. Dário Oficial da

União, Rio de Janeiro, 1940. Disponível em: <http://www.planalto.gov.br/ccivil_03/ decreto-lei/Del2848compilado.htm>. Acesso em: 11 set. 2019.

. Instrução Normativa Intersecretarial n. 1 de 24/03/1994. Diário Oficial da União,

Brasília, 1994. Disponível em: <http://www.normasbrasil.com.br/norma/instrucao-normativa-1-1994_73572.html>. Acesso em: 11 set. 2019.

. Comissão Nacional da Verdade. Violações de direitos humanos nas Igrejas

Cristãs. In: . Relatório da Comissão Nacional da Verdade. Brasília, CNV, 2014. v. 2, cap. 4. pp. 156-200. Disponível em: <http://cnv.memoriasreveladas.gov.br/images/pdf/relatorio/Volume\%202\%20-\%20Texto\%204.pdf>. Acesso em: 11 set. 2019.

. Constituição da República Federativa. Brasília, Supremo Tribunal Federal, 2018. BERNSTEIN, Eduard. Socialismo Evolucionário. Rio de Janeiro, Jorge Zahar, 1997.

BRITO, Daniel Chaves de. A SUDAM e a crise institucional do desenvolvimento na Amazônia. Papers do NAEA, n. 96, Belém, 1998.

BUNKER, Stephen. Underdevelopment the Amazon. Chicago, The university Chicago Press. 1985.

CASALDÁLIGA, Pedro. Uma Igreja da Amazônia em conflito com o latifúndio e a marginalização social. Mato Grosso: [s.n], [19- -]

COMISSÃO PASTORAL DA TERRA. Conflitos no Campo Brasil. Goiânia, CPT, 19852017. Disponível em: <https://www.cptnacional.org.br/index.php/publicacoes-2/ conflitos-no-campo-brasil>. Acesso em: 11 set. 2019.

ESTERCI, Neide. Escravos da Desigualdade: estudo sobre o uso repressivo da força de trabalho hoje. Rio de Janeiro, CEDI, Koinonia, 1994.

FIGUEIRA, Ricardo Resende. Condenados à Escravidão. In: Comissão Pastoral da Terra. Trabalho Escravo no Brasil Contemporâneo. Goiânia; São Paulo, Ed Loyola e CPT - Comissão Pastoral da Terra, 1999. 
HABERMAS, Jurgen. Direito e Democracia: entre facticidade e validade. Rio de Janeiro, Tempo Brasileiro, 1997.

HASHIZUME, Maurício. Crime, castigo e salvação. In: Comissão Pastoral da Terra Conflitos no Campo Brasil 2009. Goiânia, CPT, 2010.

OLIVEIRA, Ariovaldo Umbelino. Agricultura brasileira transformações recentes. Geografia do Brasil. In: ROSS, Jurandyr Luciano Sanches (org.). São Paulo, Edusp, 2009.

KANT, Immanuel. Fundamentação da metafísica dos costumes. São Paulo, Discurso Editorial, Barcarolla, 2009.

LEPARGNEUR, François Hubert. A Igreja e o reconhecimento dos direitos humanos na história. São Paulo, Cortez \& Moraes, 1977.

MAINWARING, Scott. A Igreja Católica e a política no Brasil (1916-1985). São Paulo, Brasiliense, 1989.

MARINI, Rui Mauro. Subdesarollo y Revolución. México, Siglo Veintiuno, 1969.

MARTINS, José de Souza. A escravidão nos dias de hoje e as ciladas de interpretação: reflexão sobre riscos de intervenção subinformada In: Comissão Pastoral da Terra. Trabalho Escravo no Brasil Contemporâneo. Goiânia; São Paulo, Ed. Loyola e CPT Comissão Pastoral da Terra, 1999.

MARX, Karl. O Capital - Crítica da Economia Política. São Paulo, Boitempo, 2013.

MORAES, Maria José de Souza. Trabalho escravo: da omissão do Estado a CONATRAE passando pela bicicleta do Padre Canuto. Disponível em: <http://www.prelaziasaofelixdoaraguaia.org.br/trabalhoescravo.htm>. Acesso em: 27 fev. 2018. Sem data.

Quando o trabalho é incompatível com a dignidade humana. In: Comissão Pastoral da Terra Conflitos no Campo Brasil 2006. Goiânia, CPT, 2007.

NIETZSCHE, Friedrich. Sobre Verdade e Mentira no Sentido Extra-Moral. In: Nietzsche Obras Incompletas. Coleção: Os Pensadores, São Paulo, Abril, 1983.

PLASSAT, Xavier. Nova geografia do trabalho escravo brasileiro: mudança ou revelação? In: Comissão Pastoral da Terra Conflitos no Campo Brasil 2008. Goiânia, CPT, 2009.

ROUANET, Sergio Paulo. Dilemas da moral iluminista. In: NOVAES, Adauto. Ética. São Paulo, Companhia das Letras, 2007.

SAKAMOTO, Leonardo. A reinvenção capitalista do trabalho escravo no Brasil. In: Comissão Pastoral da Terra Conflitos no Campo Brasil 2007. Goiânia, CPT, 2008.

SILVA, Maria Aparecida de Moraes. Mortes e acidentes nas profundezas do "mar de cana" e dos laranjais paulistas. INTERFACEHS Revista de Gestão Integrada em Saúdo do Trabalho e Meio Ambiente, v. 3, n. 2 abr.-ago., 2008.

SUTTON, Alison. Trabalho escravo: um elo na cadeia da modernização no Brasil de hoje. São Paulo: ASI, 1994. 
VATICANO. Constituição Pastoral Gaudium et Spes sobre a Igreja no mundo atual.

Vaticano, S.d. Disponível em: <http://www.vatican.va/archive/hist_councils/ii_ vatican_council/documents/vat ii_const_19651207_gaudium-et-spes_po.html $>$. Acesso em: 27 fev. 2018. Sem data.

WILDE, Melissa. Vatican II: a sociological analysis of religious change. Princeton, Princeton University Press, 2007.

Recebido em: 27/02/2018

Aprovado em: 04/07/2019

\section{Como citar este artigo:}

QUEIROZ, Pedro Henrique Santos. O conceito de trabalho escravo da Comissão Pastoral da Terra (CPT): trajetória e dilemas (1970 - dias atuais). Contemporânea Revista de Sociologia da UFSCar, v. 9, n. 3, set.- dez. 2019, pp. 875-897. 